\title{
Prototype Traffic Light Long Range Communication System Based on Air Pollution
}

\author{
Ahmad Maulid Asmiddin¹, Zulfajri Basri Hasanuddin², Syafruddin Syarif ${ }^{3}$ \\ ${ }^{1}$ Department of Telecommunications and Information Engineering, Electrical Engineering, \\ Faculty of Engineering, Universitas Hasanuddin Makassar, Indonesia. 92119 \\ ${ }^{23}$ Department of Electrical Engineering, Faculty of Engineering, Universitas Hasanuddin \\ Makassar, \\ Indonesia. 92119 \\ \{ahmadmaulid22@gmail.com¹, zulfajri@unhas.ac.id², ssyariftuh@gmail.com³
}

\begin{abstract}
The use of the microcontroller as a communication and remote control of traffic light is currently known to not utilize maximally. This research aims to design a communication system and long distance traffic light dick and test and analyze the performance of the built-in system traffic light. The method used in this study is an experimental, experimental method here, which is to build a long distance traffic light communication system integrated LM35 temperature sensor, DHT11 humidity and MQ2 smoke by utilizing a microcontroller, Borland Delphi, Basic Comapiler (BASCOM), ProgISp, Wavecom Modem, downloader and Short message service (SMS) and the data collection process is carried out for 24 hours. The results of this study indicate that the system built can automatically control the traffic light by utilizing CO sensor readings, LM35 temperature and DHT11humidity.
\end{abstract}

Keywords: Traffic light, Microcontroller, Short Message Service Sensors, Basic Compiler.

\section{Introduction}

The population of vehicles on the road from day to day is growing rapidly. This situation can lead to congestion that affects the mileage that must be passed by the driver, the driver deliberately violating the traffic rules that have been applied, the density of vehicles can also affect respiratory problems caused by air pollution from vehicles. The existence of Traffic Light or commonly called warning lights is very necessary considering the vehicle volume numbers that are getting more and more dense. The volume of vehicles in big cities and developing cities is quite dense, especially in the mornings when road users start their activities as well as in the afternoon when the road users start leaving their activities. Based on the description above, it is necessary to have traffic light system that can provide convenience andprovide benefits especially for driver. This communication system can provide control signals on a mobile to the desired traffic point. 


\section{Material and Methods}

This type of research is applied experimental research so that from the scope of the problem can be studied library research, methods of collecting field data and making the system. Data collection techniques are Calibrating the Humidity Sensor Temperature Sensor and MQ2 sensor. This stage is carried out for 24 hours to find out readings from temperature and humidity sensor data and MQ2 sensors. From the data obtained is made a reference in the threshold determination process on the traffic light. Search conditions for R0 values or fresh air parameters are needed to calculate $\mathrm{CO}$ values to set the traffic parameter threshold at the intersection. $\mathrm{CO}$ value on the road must have a $\mathrm{RO}$ value reference obtained from the conditions in the fresh air condition.

The instruments used in this study are:

1. Computer with an Intel® Core TM i3-5005U CPU @ 2.00 GHz, 4GB RAM and 64-Bit Enterprise Windows 10 (10.0, Build 10586)

2. Bascom AVR IDE 2.0.75 software

3. ProgISP Software Version 1.72

4. Delphi 7 Programming Software

5. Minimum ATMega16 microcontroller system module, LM35 temperature sensor, DHT11 sensor, MQ2 sensor and a set of xiaomi android smartphones.

The work system design is divided into three sub-system parts, namely the sub-system on the traffic light side, the sub-system in the office control and the sub-system on the mobile control.

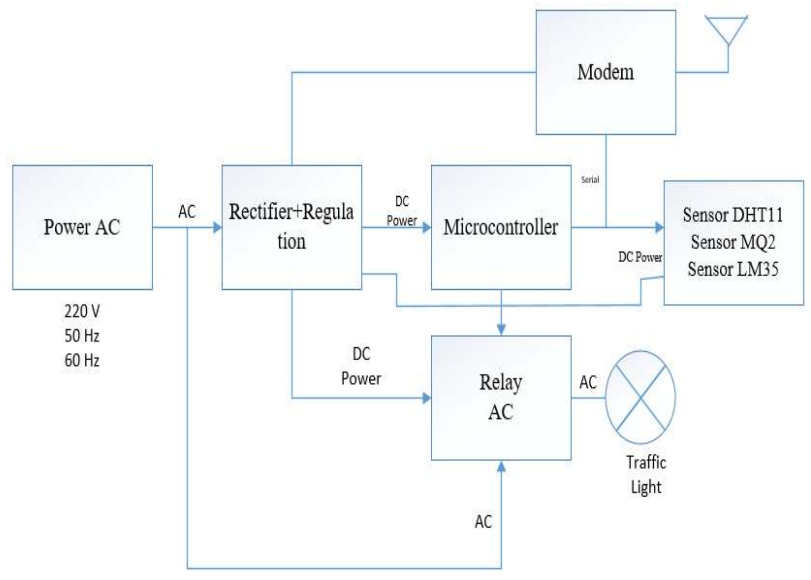

Fig 1. Traffic light sub system

Based on the figure 1 there are seven sub system in the traffic light, such as power ac, rectifier and regulation, microcontroller, relay, modem, sensor and traffic light.

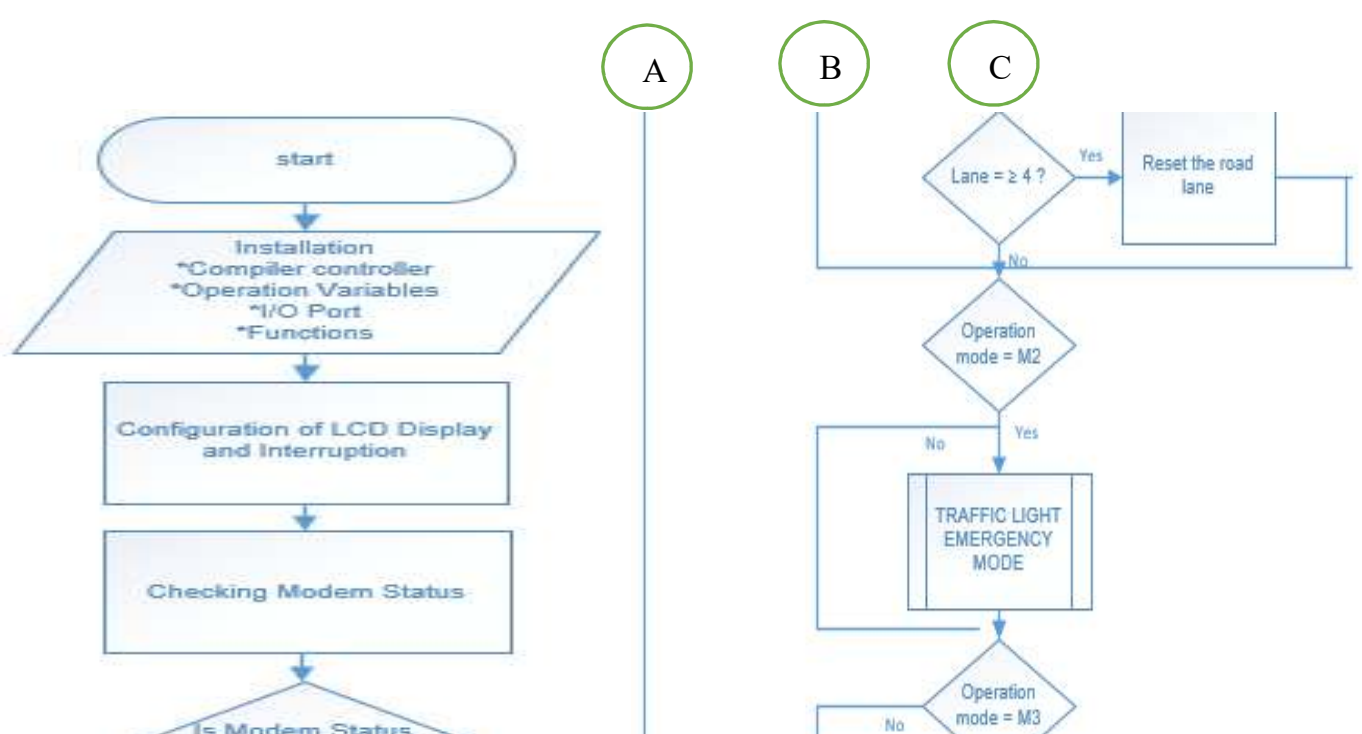




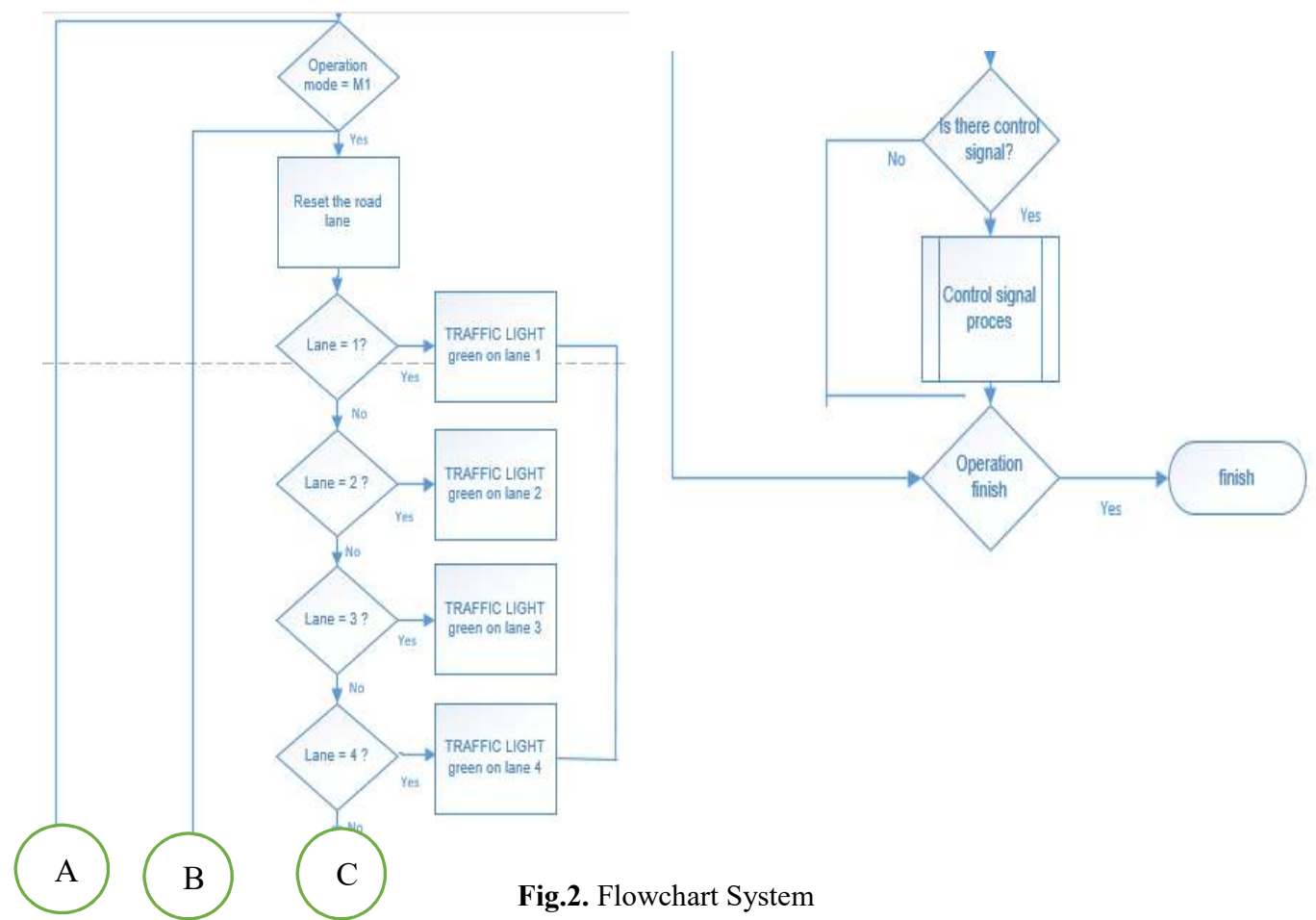

In this system design flowchart begins with the initial process when opening the system program, the next process is doing an initialization process in which there is an initialization process of input compiler, operating variables, I / O ports and functions Its function. After the initialization process, the program is then entered into the LCD viewer configuration and interruptions. After that, check the Modem status if the modem status is not connected. Then again check the LCD viewer configuration and its interruptions., operating parameters, operating mode and operating mode M1 if Yes mode M1 will update the path and if path $=1$ ? the traffic light process on line one shows the traffic light is green and if path $=2$ ? if yes the traffic light is declared green on the second path, if path $=3$ ? if yes then the traffic light path 3 is green on the third line and if path $=4$ ? If yes the traffic light is green on the fourth path, and if the path is $\geq 4$ ? if yes, reset the path and if it will not loop to the initial process, which is Operation Mode $=$ M1 ?. 
Next in M2 operation mode, if the operating mode $=$ M2 if yes, the emergency mode traffic light process will be carried out and if it will not check again in operation mode $=\mathrm{M} 2$. After that at the next stage Operation mode $=$ M3 ? if yes, the next process will display the traffic light in the vehicle meeting mode and then check the modem terminal in the delay period and operating control indicators.

Then the process will be carried out if there is a control signal so the process will be forwarded to the control signal process and if it is not going to be done looping checks whether there is a control signal or not. And after it is stated that there is a control signal process then the process is declared complete.

\section{Results and Discussion}

In general, the system is divided into three parts or sub-systems, are the sub-system of the side traffic light, sub-system side of the office and the sub-system of mobile control. This subsystem that works to regulate the mode and working position of the traffic light, control of this system can be given through the control side in the office and can also be given the mobile control side. On the control side, the office can monitor and provide control in the form of a sub-system working mode on the traffic light side, as well as on the mobile control side the office control side is fixed static while in the mobile control the control can be done mobile. The traffic light side operation mode is M1, M2 Mode and M3 Mode. In M1 mode, the traffic light works as well as in general. In M2 Mode is an interrupt or emergency mode. In M3 Mode is the control mode based on the density level.

\subsection{Hardware System}

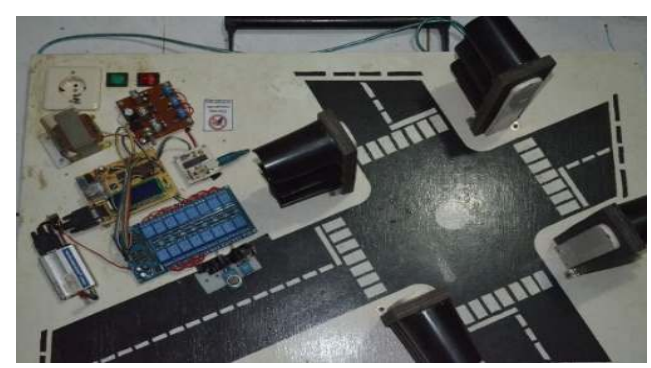

Fig.3. Series of Overall Traffic Light System

This system consists of several sub-systems is the AC stepdown sub system, rectifier and regulation module then there is a microcontroller sub-system then the sub-system for control and the LCD, system downloader, sub system relay, the modem sub-system, the sensor subsystem and the sub-system traffic light lamp. Sub system of voltage reduction or stepdown $\mathrm{AC}$ converts the input voltage of 220 volts in the primary part is changed to a voltage of 20 volts in the secondary part, the 20 Volt AC in the rectifier module and the regulation is then rectified by a rectified full wave rectifier brightreghtifire mechanism which is then regulated into several DC voltage levels. Energy sources derived from regulation are used to turn on the sub system of downloader control then relay systems, sensors and modem. The microcontroller sub system to work must be programmed, to program it using Bascom Language, the program after the compiler then the program is downloaded to the microcontroller via a USB downloader. The program after being compiled is then downloaded via a downloader to be saved to the microcontroller. Programs that are made contain routines to control LCDs, relays, control 
modems and control sensors and control relay to traffic. The way it works is the microcontroller to turn on the AC traffic light source then it will use a relay The relay function when connecting and turning off the traffic light comes from the control signal provided by the microcontroller through I / O pins connected by the relay system. To turn on the light of the microcontroller gives the high logic to the output the logic high then gives input to the relay. Because this smart traffic light can be controlled by a mobile device, this control system will also regulate how to control this modem to transmit its state and receive mobile control signals originating from the mobile control side. Communication between the microcontroller and modem is via serial communication. Serial communication is used when the mobile control sends a control signal to one mode, then the control signal will be received by the modem then serial communication will be read by the microcontroller and microcontroller then based on the control signal it will configure the operation.

In one of the traffic light system modes it works based on vehicle density, in this case the vehicle density is measured through 2 sensors with three environmental indicators namely MQ2 sensor calibrated with CO smoke or carbon monoxide, DHT11 is used to read environmental parameters related to temperature and humidity. The MQ2 sensor is calibrated to be able to read CO or carbon monoxide, then DHT11 is used to read temperature and environmental parameters. Parameters of temperature, humidity, and CO that come from vehicles which then make changes to the state of the environment will be read by both sensors and then the microcontroller will process sensor readings into quantities of humidity temperature and carbon monoxide or CO.

The temperature of the humidity and carbon monoxides in the calibration stage are known for their respective thresholds and the readable values will be compared by the threshold. If it shows a dense threshold, then on the sensor side it reads the control system will order the relay to blame the green light on that side while on the other side it will be red. Vice versa for different sides. But the other modes are used for emergencies, namely modes that we can interrupt one side of the lamp to light green and the other red.

This mode is used when the need for traffic light is set. For example, to welcome country guests who pass the intersection, the way it works is the officer or the operator on duty will provide emergency control signals. Control signals for utilization mode or blame green lights on one side. The control signal is then processed and when the control system reads its emergency mode, the microcontroller will control the logic output from the relay to blame the green light on one side. In addition, of course the mode that is generally the third mode of traffic light is that it lights up according to a certain sequence and every change in condition from green to red or vice versa in a certain time in that mode then the control signal simply uses the internal timer inside to configure Based on the time and direction of rotation.

\subsection{Software System}

After the steps to open the system program are carried out, then enter the program file in Bascom AVR as shown in the picture below:

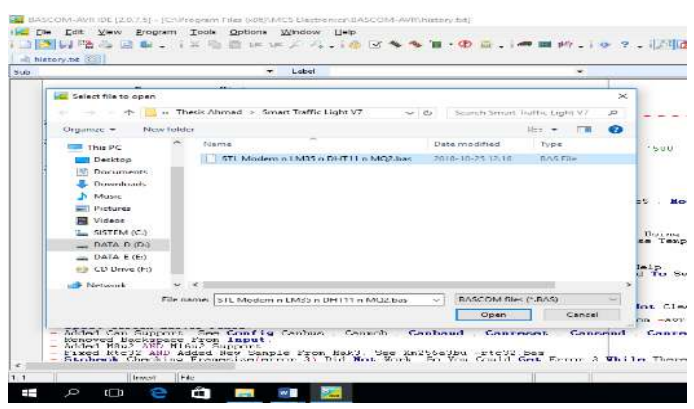


Fig.4. Traffic light program input process

After the steps to open the system program are carried out, then enter the program file in Bascom AVR as shown in the picture below:

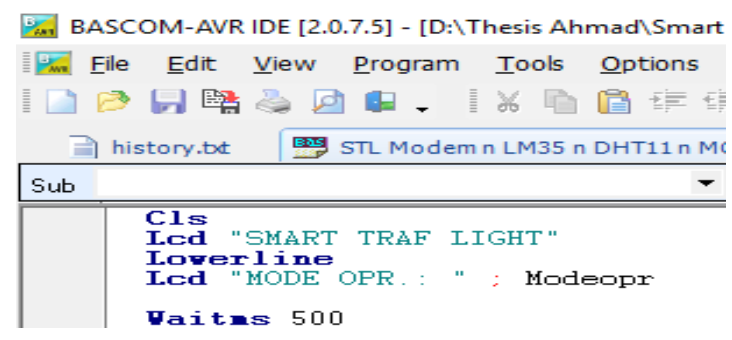

Fig.5. Initial Display Selection of Operation Mode

In M1 mode, the control pin only functions as an output to control the relay. Relay configuration is adjusted to traffic lights in general. If what happens is the M1 mode, then the traffic light works as well as in general, which turns on at a certain period according to a certain direction of rotation. Switching traffic lights is adjusted to the clockwise direction and according to the specified time. If the mode selection is M1, the procedure and command are as shown in the image below:

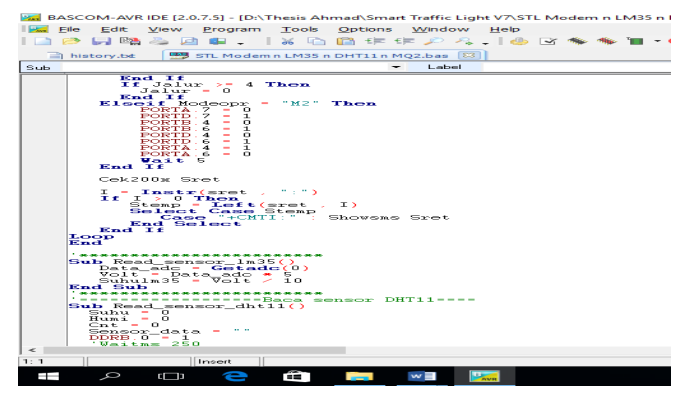

Fig.6. M1 Mode Selection

If the mode selection is M2, the procedure and command are as shown in the image below:

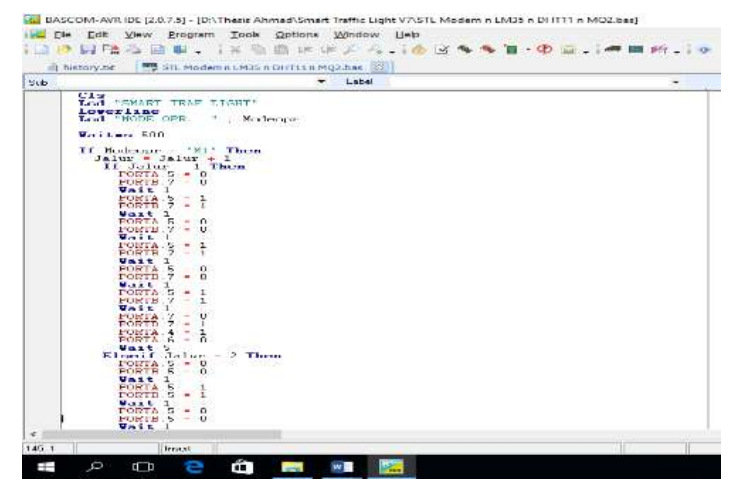

Fig.7. M2 Mode Selection 
M2 Mode is an emergency mode, turned on one side, the control is via relay but the traffic configuration is adjusted to the desired green direction. In this case when we want to turn green on one of the road points, then the other point at the intersection will be automatically red.

The M3 mode is based on sensor readings at the intersection. The procedures and commands are shown in Figure 8. M3 is a control mode based on density. Density of the vehicle known through the sensor installed is then processed by a microcontroller that functions to determine the density on one side of the road and can be used as the basis for on / off traffic light configuration. In this mode the sensors that have been installed at one intersection point read the state of temperature humidity and carbon monoxide gas. When the sensor reading process found the amount of pollution at one of the crossing points, then the vehicle at that point experienced density, so from that point the one that experienced the highest level of density and the amount of pollution would be green and other points reddish. In this study focused on one of the crossing points.

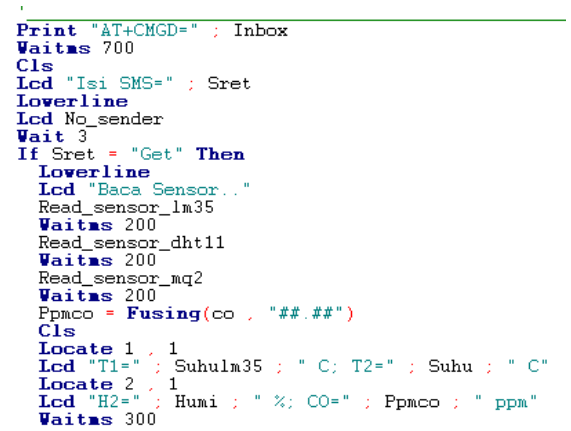

Fig.8. M3 Mode Selection

\subsection{Analysis of Calculation and Determination of Fresh Air/R0}

The process of taking R0 or fresh air is done on 04-04-2017 until 07-04-2017. The data obtained between this time is 5123 data. The data collection process is carried out within 24 hours. The GPS position at the time of data collection on 04-04-2017 is Elev: 504Ft, S: 05.48644 *, E: $122.58380 *$ and 07-04-2017 is Elev: $518 \mathrm{Ft}, \mathrm{S}: 05.48645 *$, E: $122.58384 *$.

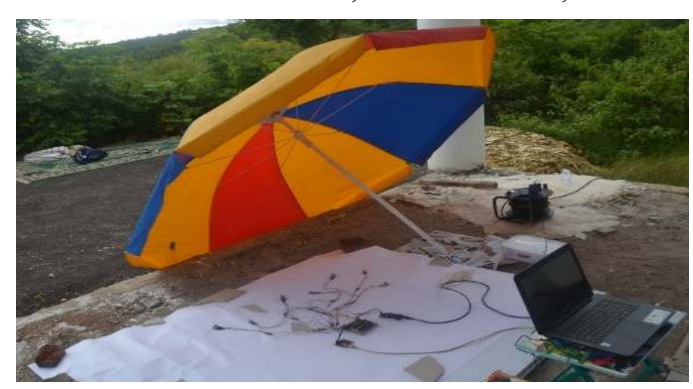

Fig.9. 24 Hours R0 data collection

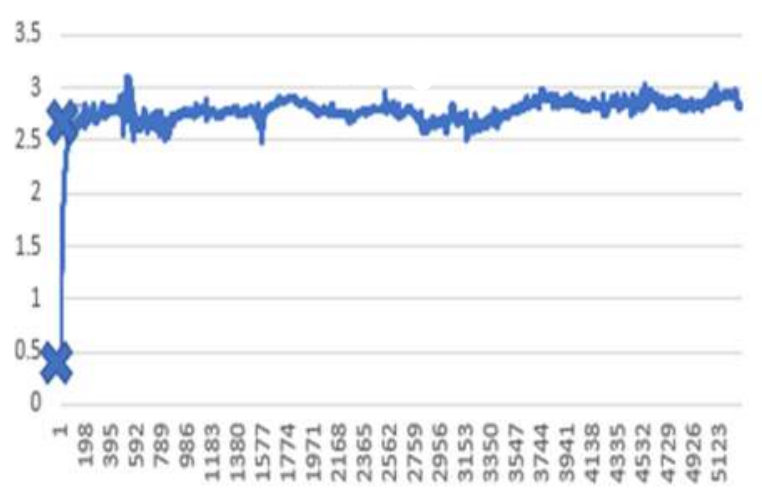


Fig.10. R0 Graph

The RO graph in the picture above shows that the initialization process starts from the first data in the picture labeled $X$ which starts at 5:22:32 until data 190 at 6:14:44. The transition process on the R0 chart is started from 190 data starts at 05:22:32 PM until the data to 580 hours 08:02:28 PM. The graphical convergence or steady direction above shows between data 682 at $08: 30: 38$ PM on 04-06-17 to data 5125 dated 04-07-17 hours 05:43:44 PM. The average MQ2 sensor reading in the data collection process in the 24 hours period is $\mu=2,77$, the maximum value $(\operatorname{Max})=3.09$ the minimum value $(\operatorname{Min})=0.56$ and the standard deviation $\sigma=$ 0.13 .

\subsection{Traffic Parameter Threshold Analysis}

Traffic light parameter threshold assessment in this study is divided into 4 parts. The first part is the average value of the threshold on the traffic light side, the second is the Standard deviation 1, the third is the assessment of the Standard Deviation 2 parameter and the fourth is the Standard Deviation threshold 3. In the process the average value obtained from the system trial the average value of the traffic threshold parameter is 2.28. The value of the Standard Deviation $(\sigma) 1$ is 9.87 , the value obtained from the Standard Deviation $(\sigma) 2$ is 17,61 and for the value obtained for the Standard Deviation $(\sigma) 3$ is 25,28 .

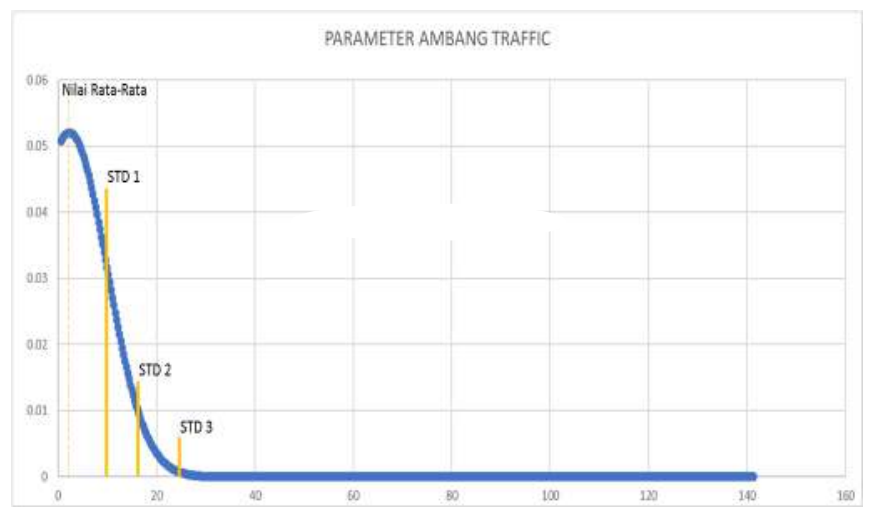

Fig.11. Traffic light threshold parameter

Determination of threshold is based on testing tools in the field based on the greatest value in each sensor reading, from the tests classified several parameters of traffic namely normal traffic threshold, congested traffic threshold, and very heavy traffic threshold. From several tests in this study set the average taken by means of equipment turned on at a particular waypoint, because of the different characteristics of the road so we only determine the position of the tool at one of the intersection. The average value of the temperature obtained for testing in the normal condition of the vehicle is $29^{\circ} \mathrm{C}$, humidity $=76 \%$, MQ2 $(\mu)$ in normal conditions of vehicles tend to be normal with an average value of 5.52 and standard deviation is 2.68 . The average temperature obtained for vehicle full testing $32^{\circ} \mathrm{C}$, humidity $=60 \%$ and the average value of testing MQ2 is 12.78 and standard deviation is 2.00 . Average temperature obtained for testing a very dense state of the vehicle is $35^{\circ} \mathrm{C}$, humidity $57 \%$ and the average value of testing MQ2 is 19.59 and standar deviation is 1.88 . 


\section{Conclusion}

The long range traffic light communication system based on the amount of air pollution has been designed by utilizing microcontrollers, sensors, modems, Short Message Service and in the results of system trials in the field in various situations, such as normal vehicles, dense vehicles, increasingly dense vehicles and very dense the vehicle obtained a value in the form of sensor readings that can be used as a reference for controlling traffic light lights by providing control signals in the form of operating modes M1(then the traffic light works as well as in general) M2 (emergency mode) and M3(control mode based on density).

\section{References}

[1] Atmoko, Rachmad Andri. Sistem Monitoring dan Pengendalian Suhu dan Kelembaban Ruang pada Rumah Walet Berbasis Android, Web, dan SMS. Semantik 3.1 (2013).

[2] Cao Z, Jiang S, Zhang J, Guo H. A Unified Framework for Vehicle Rerouting and Traffic Light Control to Reduce Traffic Congestion. IEEE Trans Intell Transp Syst. 18(7):1958-1973. doi:10.1109/TITS.2016.2613997 (2017)

[3] Deri, Gema Alfarisi, m. Ichwan, Lita Lidyawati. Implementasi Sistem SMS Gateway untuk Kendali Air Conditioner. REKA ELKOMIKA 1.2. (2013).

[4] Dubey, Alka, Mohd Shamshad, Kamlesh Patel. Design and implementation of pollution monitoring and recording system using microcontroller. (2015)

[5] Ghazal B, Elkhatib K, Chahine K, Kherfan M. Smart traffic light control system. In: 2016 3rd International Conference on Electrical, Electronics, Computer Engineering and Their Applications, EECEA. doi:10.1109/EECEA.2016.7470780 (2016)

[6] Khattak \& Muhammad Arshad. PLC based intelligent traffic control system. International Journal of Electrical \& Computer Sciences IJECS-IJENS 11.06 (2011).

[7] Kumaravel S, Prabha S. Adaptive Data Traffic Control with Wireless Sensor Networks. 2(3):200-208. (2012)

[8] Lämmer S, Helbing D. Self-control of traffic lights and vehicle flows in urban road networks. J Stat Mech Theory Exp. (4). doi:10.1088/1742-5468/2008/04/P04019 (2008)

[9] Levinson J, Askeland J, Dolson J, Thrun S. Traffic light mapping, localization, and state detection for autonomous vehicles. Proc - IEEE Int Conf Robot Autom. 5784-5791. doi:10.1109/ICRA.2011.5979714 (2011)

[10] Li, Chunxiao, Shigeru Shimamoto. An Open Traffic Light Control Model for Reducing Vehicles'\$hbox $\{\mathrm{CO}\}$ _ $\{2\}$ \$ Emissions Based on ETC Vehicles. IEEE Transactions on Vehicular Technology $\overline{61.1}$ 97-110 (2012).

[11] Li L, Wen D, Yao D. Vehicular Communications. (1):1-8. (2013)

[12] Muchtar, Husnibes, Asep Hidayat. Implementasi Wavecom Dalam Monitoring Beban Listrik Berbasis Mikrokontroler. Jurnal Teknologi 9.1: 1-5. (2017).

[13] Mustarang, Alhusen, Hapsoro Agung Nugroho. Sistem Kontrol Catu Daya, Suhu Dan Kelembaban Udara Berbasis Atmega 2560 Pada Ruang Bunker Seismometer. Simetris: Jurnal Teknik Mesin, Elektro dan Ilmu Komputer 8.1: 265-272 (2017).

[14] Rofiq, Muhammad, Yusron. M. Perancangan Sistem Kontrol dan Monitoring Lampu dengan Memanfaatkan teknologi Bluetooth pada Smartphone Android." Jurnal Ilmiah Teknologi Informasi Asia 8.1. 14-23. (2014).

[15] Simanungkalit, Aeromidi, Indra Yasri. Aspek Perancangan Monitoring Antrian Kendaraan Pada Persimpangan Lampu Merah. Jurnal Online Mahasiswa (JOM) Bidang Teknik dan Sains 4.1: 1-8. (2017). 
[16] Wen W. A dynamic and automatic traffic light control expert system for solving the road congestion problem. Expert Syst Appl. 34(4):2370-2381. doi:10.1016/j.eswa.2007.03.007 (2008)

[17] Wijaya, Mulyapriadi, Tjandra Susila. Sistem keamanan brankas secara otomatis berbasis mikrokontroler dengan menggunakan sms serta pin dan rfid. Tesla untar 18.2 139-151 (2017)

[18] Yousef, Khalil M, Mamal N. Al-Karaki, Ali M. Shatnawi. Intelligent traffic light flow control system using wireless sensors networks." J. Inf. Sci. Eng. 26.3: 753-768 (2010).

[19] Yudanto, Adhitya Yoga, Marvin Apriyadi, Kevin Sanjaya. Optimalisasi Lampu Lalu Lintas dengan Fuzzy Logic. Universitas Multimedia Nusantara Tangerang 5.2 (2013). 